Piotr Michalski ${ }^{1}$, Agata Kosobucka ${ }^{1}$, Łukasz Pietrzykowski ${ }^{1}$, Michał Kasprzak², Katarzyna Buszko ${ }^{3}$, Karolina Obońska², Tomasz Fabiszak², Aldona Kubica ${ }^{1}$

${ }^{1}$ Department of Health Promotion, Collegium Medicum, Nicolaus Copernicus University, Lukasiewicza St., Bydgoszcz, Poland

2Department of Cardiology and Internal Diseases, Collegium Medicum, Nicolaus Copernicus University, Bydgoszcz, Poland

${ }^{3}$ Department of Theoretical Foundations of Biomedical Science and Medical Informatics, Collegium Medicum,

Nicolaus Copernicus University, Bydgoszcz, Poland

\title{
Effectiveness of therapeutic education in patients with myocardial infarction
}

\author{
Corresponding author: \\ Aldona Kubica RN, PhD \\ Department of Health Promotion, \\ Collegium Medicum, \\ Nicolaus Copernicus University \\ Lukasiewicza St. 1 \\ 85-821 Bydgoszcz, Poland \\ E-mail: aldona.kubica@gmail.com
}

Medical Research Journal 2017; Volume 2, Number 3, 89-96 10.5603/MRJ.2017.0011 Copyright (C) 2017 Via Medica ISSN 2451-2591

\begin{abstract}
Introduction. Notwithstanding the development of modern diagnostic-therapeutic techniques, cardiovascular diseases still pose a grave health, social, and economic issue. Patients hospitalised for acute coronary syndrome should, in addition to establishing an optimal pharmacotherapy, be made aware of how to prevent this disease and recognise it using its typical symptoms and signs.

Objective. The objective of the study was to evaluate the effectiveness of educational intervention based on educational brochures in patients with myocardial infarction with regard to socio-demographic factors and baseline patients' knowledge.

Material and methods. The single-centre, prospective, observational study was conducted in a cohort of 248 patients with myocardial infarction (women $n=72$, men $n=176$ ), hospitalised between May 2015 and July 2016. Consistently with the results of univariate analysis, multivariate analysis identified age $(-3.73 / 10$ years; $p<0.0006)$ and the level of education $(10.37 ; p<0.0001)$ as independent factors influencing patients' prehospital knowledge.

Results. According to multivariate analysis of the level of knowledge following the educational intervention, the only factors affecting the process of learning were age $(-2.04 / 10$ years; $p<0.03)$ and remaining in a steady relationship (9.7; $p=0.0003)$. Among factors influencing the increase of knowledge, only the level of education was of statistical significance $(-6.09 ; p<0.02)$.

Conclusions. The educational brochure proved to be an effective tool for therapeutic education, allowing minimisation of the disparities between the examined groups and improvement of the breadth of patients' knowledge.
\end{abstract}

Key words: therapeutic education, myocardial infraction, educational brochure

Med Res J 2017; 2 (3): 89-96

\section{Introduction}

Despite unequivocal and undisputed development of the modern diagnostic-therapeutic methods, cardiovascular diseases still constitute a serious health, social, and economic problem [1]. In Poland, nearly half of all deaths are attributed to cardiovascular diseases. According to statistical data, cardiovascular morbidity and mortality in our country is still high in comparison with other European Union countries [2, 3].

Following the guidelines of the European Society of Cardiology, prevention is mainly addressed at patients suffering from atherosclerosis-related cardiovascular diseases [4]. Patients hospitalised for acute coronary syndrome, prior to discharge from hospital, should gain sufficient knowledge of prevention and signs and symptoms of this disease. Of key importance is also the patient's active participation in the process of constructing his/her personal therapeutic plan.

Educational brochures are one of the most popular sources of medical information, allowing patients to become familiarised with the educational material at their convenience. The low costs of this method of education appear to be yet another advantage. The primary drawback of this method, however, is the continuous need for effective motivation of patients to use this educational source. The patient and the family are then required to show an active stance and eagerness to familiarise themselves with the information provided in this form $[5,6]$. 
The aim of the study was to assess the effectiveness of educational intervention based on an educational brochure, in patients with myocardial infarction, with regard to socio-demographic factors and baseline patients' knowledge.

\section{Material and methods}

The study, designed as single-centre, prospective, observational study, was approved by the Bioethics Committee at L. Rydygier Collegium Medicum in Bydgoszcz, Nicolaus Copernicus University in Toruń (approval reference no. KB 312/2015; $21^{\text {st }}$ April 2015). The research was performed in accordance with the ethical principles that have been laid down in the Declaration of Helsinki and was consistent with the International Conference on Harmonization/Good Clinical Practice and applicable regulatory requirements.

All consecutive patients with AMI (both ST-elevation $\mathrm{MI}$ and non-ST elevation $\mathrm{MI}$ ) and treated with percutaneous coronary intervention $(\mathrm{PCl})$ at $\mathrm{A}$. Jurasz University Hospital (Bydgoszcz, Poland) between May 2015 and July 2016, with exclusion of patients admitted to hospital on weekends, were screened for eligibility to participate. Patients arbitrarily judged by investigators to be able to use the educational brochure according to their clinical conditions and mental properties (396 of 507 ) were considered eligible to be enrolled into the study. Finally, 300 patients provided written informed consent to participate in the study.

The study population comprised 248 patients (women $\mathrm{n}=72$, men $\mathrm{n}=176$ ), aged 30-91 years (mean age: $62 \pm 11$ years), who provided all answers to survey questions evaluating patients' knowledge twice: during the first 48 hours of hospital stay $\left(1^{\text {st }} \mathrm{knowledge}\right.$ evaluation $-1 \mathrm{KE}$ ) and on the day of hospital discharge ( $2^{\text {nd }}$ knowledge evaluation $-2 \mathrm{KE}$ ). The socio-demographic data are presented in Table 1. Fifty-two patients initially enrolled into the study were excluded from the analysis due to inability to fill out the questionnaire $(n=17)$, refusal to undergo $2 \mathrm{KE}(\mathrm{n}=16)$, premature discharge from the department of cardiology $(n=15)$, or death $(n=4)$.

A survey evaluating patients' knowledge of ischaemic heart disease and its consequences, i.e. myocardial infarction, was conducted using a questionnaire consisting of 20 single-choice questions. Each correct answer earned one point. The questionnaire included questions pertaining to the knowledge of signs and symptoms of the disease, the disease itself, and prevention of the disease. After the $1 \mathrm{KE}$, patients were provided with an educational brochure entitled "Myocardial Infarction", which comprised the information necessary to answer all questions in the questionnaire. All patients were actively encouraged to use this educational tool. The effectiveness of this educational intervention was assessed by comparing $1 \mathrm{KE}$ with $2 \mathrm{KE}$. Results were analysed with regard to socio-demographic factors and baseline patients' knowledge (1KE). The variables taken in account were: sex, age, education level, employment status, economic status, place of residence, marital status, and living alone or with family. The variables were arbitrarily chosen by investigators as factors potentially modifying the effectiveness of therapeutic education. To ensure completeness of the collected data and to avoid potential bias caused by impact of other persons the questionnaire was filled out by the investigated patient in the investigator's presence. Researchers undertook special care to not influence patients' answers.

Statistical calculations were performed using the Statistica 12.0 package (StatSoft, Tulsa, OK, USA). The results are presented as the mean percentage of

Table 1. The characteristics of the examined group

\begin{tabular}{|c|c|c|}
\hline Variable & $\begin{array}{l}\text { Amount } \\
\text { (n) }\end{array}$ & $\begin{array}{l}\text { Percentage } \\
\text { of the total (\%) }\end{array}$ \\
\hline \multicolumn{3}{|l|}{ Sex } \\
\hline Women & 72 & 29.0 \\
\hline Men & 176 & 71.0 \\
\hline \multicolumn{3}{|l|}{ Age } \\
\hline$<65$ years & 140 & 56.5 \\
\hline$\geq 65$ years & 108 & 43.5 \\
\hline \multicolumn{3}{|l|}{ Education } \\
\hline Primary education & 33 & 13.3 \\
\hline Basic vocational education & 89 & 35.9 \\
\hline Secondary education & 92 & 37.1 \\
\hline Higher education & 34 & 13.7 \\
\hline \multicolumn{3}{|l|}{ Employment status } \\
\hline Employed & 99 & 39.9 \\
\hline Unemployed & 15 & 6.0 \\
\hline Pensioner & 101 & 40.7 \\
\hline Invalid & 33 & 13.3 \\
\hline \multicolumn{3}{|l|}{ Economic status } \\
\hline Very good & 13 & 5.2 \\
\hline Satisfactory & 221 & 89.1 \\
\hline $\mathrm{Bad}$ & 14 & 5.6 \\
\hline Very bad & 0 & 0.0 \\
\hline \multicolumn{3}{|l|}{ Place of residence } \\
\hline Big city: $>100$ thousand & 128 & 51.6 \\
\hline inhabitants & 50 & 20.2 \\
\hline $\begin{array}{l}\text { Small town: } \leq 100 \text { thousand } \\
\text { inhabitants } \\
\text { Village }\end{array}$ & 70 & 28.2 \\
\hline \multicolumn{3}{|l|}{ Marital status } \\
\hline Single & 28 & 11.3 \\
\hline In a relationship & 182 & 73.4 \\
\hline Widow/ widower & 38 & 15.3 \\
\hline \multicolumn{3}{|l|}{ Lives } \\
\hline Alone & 31 & 13.0 \\
\hline With family & 217 & 87.0 \\
\hline
\end{tabular}




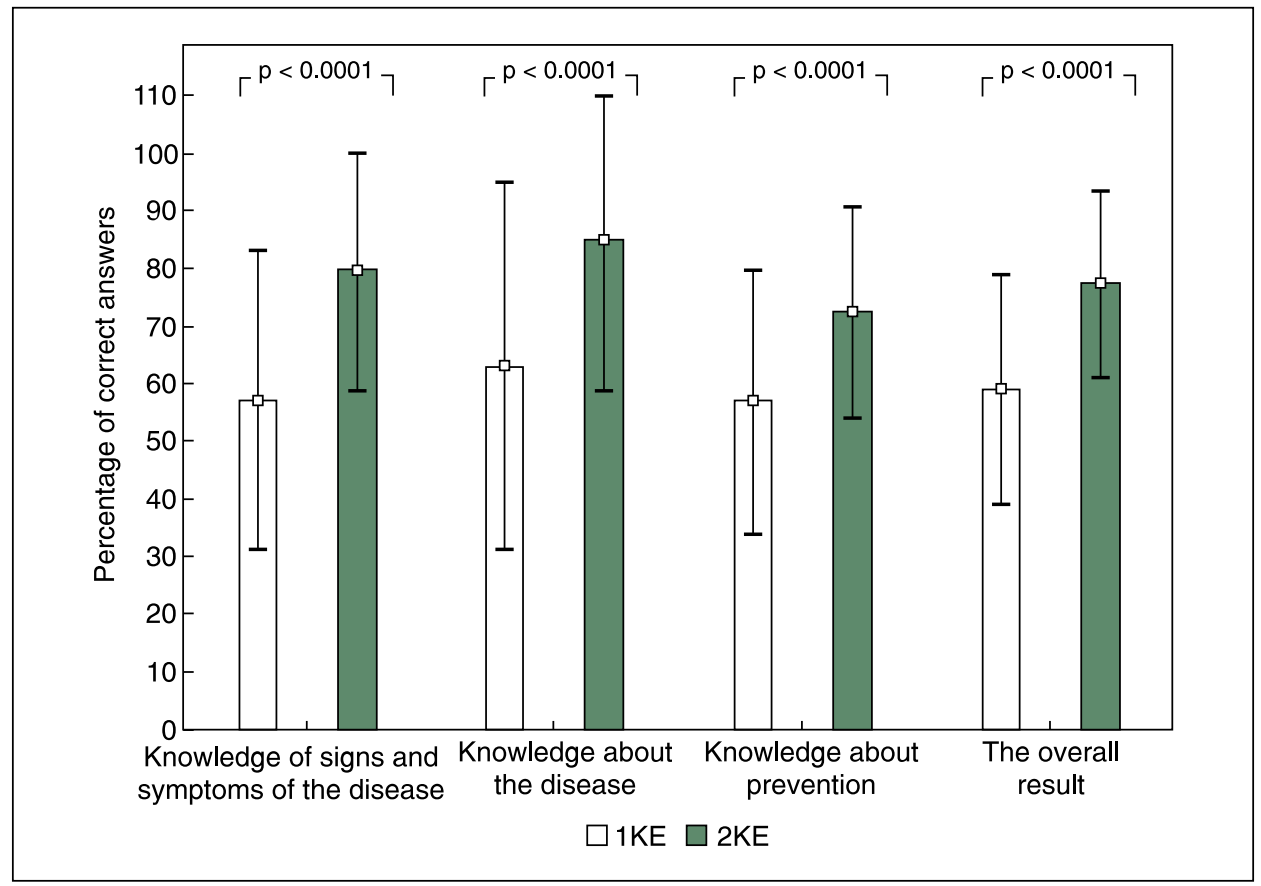

Figure 1. Evaluation of patients' knowledge at the beginning of hospitalisation (1KE) and at hospital discharge (2KE)

correct answers \pm standard deviation. According the Shapiro-Wilk test, quantitative variables did not follow normal distribution. Therefore, for group comparisons non-parametric tests were used. The variables were compared using the Mann-Whitney, the Kruskal-Wallis, and Wilcoxon tests. For interdependence evaluation between two variables the Spearman's rank correlation was applied. Values of $p<0.05$ were considered statistically significant. The influence of particular variables on patients' knowledge was assessed with multiple regression analysis. In order to select the best regression models the method of stepwise regression was applied. The initial model was constructed using all parameters showing $p$ values $<0.1$ in univariate analysis. Subsequently, statistically irrelevant variables $(p \geq 0.05)$ were successively removed from the model according to their decreasing $p$ values.

\section{Results}

A marked increase in patients' knowledge (18.71 \pm 19.68 points) was found comparing 1KE with 2 KE (Fig. 1). Additionally, a positive correlation between the results of $1 \mathrm{KE}$ and $2 \mathrm{KE}$ was observed ( $\mathrm{R}$ Spearman $=0.3953$; $p<0.000001)$. No differences between men and women were found regarding the initial knowledge or its upsurge during hospitalisation. The initial knowledge of younger patients (< 65 years of age) was more extensive at the beginning than that of elderly patients
( $\geq 65$ years of age), respectively: $(61.61 \% \pm 18.75 \%$ vs. $54.44 \% \pm 20.67 \%$; $p<0.01)$. Age-dependence was confirmed by the correlation between age and knowledge observed at the beginning of hospitalisation $(R=-0.1900, p=0.0027)$. On 1KE, significant differences regarding the knowledge of the disease $(66.86 \% \pm 29.65 \%$ vs. $57.41 \% \pm 33.16 \% ; p<0.04)$ and knowledge of prevention $(59.57 \% \pm 24.28 \%$ vs. $53.52 \% \pm 27.46 \%$ ) were found between younger and elderly patients. Due to the significantly higher growth of knowledge in the elderly patients in comparison with the younger ones $(21.62 \% \pm 19.06 \%$ vs. $16.46 \% \pm 19.92 \%$; $p<0.03$ ), the differences established at the beginning of hospitalisation were mitigated, as confirmed by the correlation between age and the growth of knowledge $(R=0.1264 ; p=0.0468)$. The $1 \mathrm{KE}$ also revealed immense dissimilarities in the knowledge of the disease and its prevention with reference to patients' level of education. The in-hospital education markedly diminished those differences, as shown on 2KE (Tab. 2).

In total, there was manifest growth in all three aspects of knowledge (regarding symptoms and signs, the disease itself, and its prevention) ( $p<0.0035)$. The increment of knowledge was highest in patients with vocational education $(22.98 \% \pm 20.21 \%)$, whose initial level of knowledge on 1KE was lowest (Fig. 2). The level of patients' knowledge also relied on their employment status. There were significant differences in the overall result on $1 \mathrm{KE}$ regarding the employment status $(p<0.004)$. The level of knowledge of the 
Table 2. Differences in the patients' level of knowledge at the beginning of hospitalisation (1KE) and at discharge from hospital $(2 \mathrm{KE})$ in relation to the level of education

\begin{tabular}{|c|c|c|c|c|c|c|c|c|c|c|}
\hline \multirow{3}{*}{$\begin{array}{l}\text { Question- } \\
\text { naire }\end{array}$} & \multirow{3}{*}{$\begin{array}{l}\text { Range of patients' } \\
\text { knowledge }\end{array}$} & \multicolumn{8}{|c|}{ Education } & \multirow[t]{3}{*}{$\mathbf{p}$} \\
\hline & & \multicolumn{2}{|c|}{ Primary } & \multicolumn{2}{|c|}{ Vocational } & \multicolumn{2}{|c|}{ Secondary } & \multicolumn{2}{|c|}{ Higher } & \\
\hline & & Mean & SD & Mean & SD & Mean & SD & Mean & SD & \\
\hline \multirow[t]{4}{*}{$1 \mathrm{KE}$} & $\begin{array}{l}\text { Knowledge of signs and } \\
\text { symptoms of the disease }\end{array}$ & 56.97 & 29.21 & 54.38 & 26.97 & 58.70 & 24.59 & 58.82 & 23.06 & NS \\
\hline & Knowledge of the disease & 52.73 & 35.29 & 56.63 & 31.22 & 67.39 & 29.46 & 75.88 & 28.19 & 0.0033 \\
\hline & Knowledge of prevention & 49.39 & 24.36 & 52.13 & 21.77 & 59.46 & 23.50 & 71.47 & 19.41 & 0.0001 \\
\hline & Total result & 52.12 & 22.91 & 53.82 & 19.56 & 61.25 & 18.79 & 69.41 & 14.66 & 0.0003 \\
\hline \multirow[t]{4}{*}{$2 \mathrm{KE}$} & $\begin{array}{l}\text { Knowledge of signs and } \\
\text { symptoms of the disease }\end{array}$ & 75.15 & 26.00 & 77.75 & 21.20 & 82.39 & 18.24 & 80.00 & 17.75 & NS \\
\hline & Knowledge of the disease & 75.76 & 31.92 & 83.37 & 26.33 & 87.61 & 21.55 & 89.41 & 22.15 & NS \\
\hline & Knowledge of prevention & 66.06 & 22.90 & 73.03 & 16.40 & 73.70 & 16.08 & 72.65 & 21.92 & NS \\
\hline & Total result & 70.76 & 22.64 & 76.80 & 14.66 & 79.35 & 12.91 & 78.68 & 17.51 & NS \\
\hline $2 \mathrm{KE}-1 \mathrm{KE}$ & Growth of knowledge & 18.64 & 17.95 & 22.98 & 20.21 & 18.10 & 19.23 & 9.26 & 18.35 & 0.0035 \\
\hline
\end{tabular}

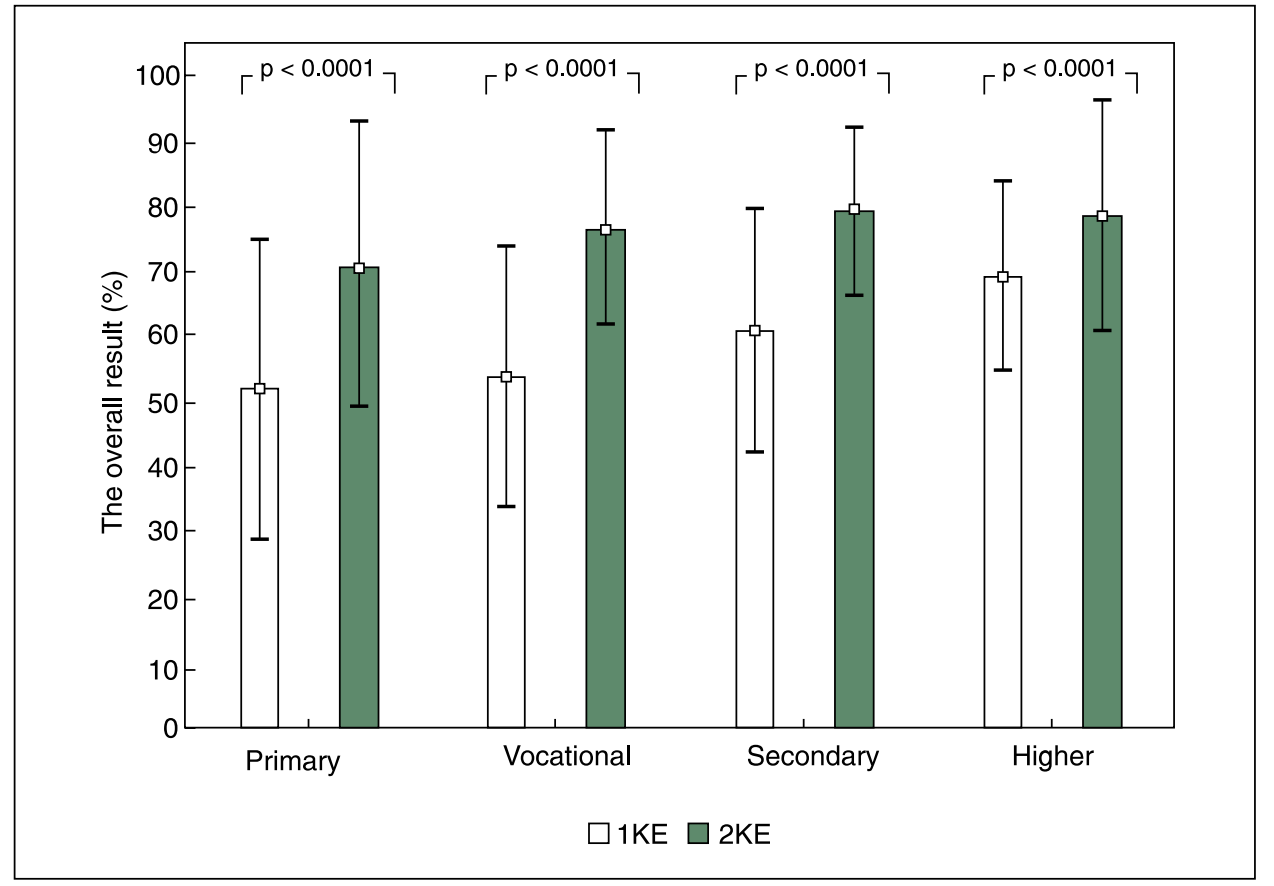

Figure 2. The evaluation of patient's knowledge at the beginning of hospitalisation (1KE) and on the day of discharge from hospital (2KE) depending on the level of education

disease $(p<0.002)$ and its prevention $(p<0.003)$ was considerably higher in patients remaining under employment in comparison with unemployed ones; however, no differences were found in the knowledge of signs and symptoms of the disease. On 2KE, the two groups did not differ with respect to the level of knowledge. The growth of knowledge, however, was significantly higher $(p<0.05)$ in unemployed patients, resulting in diminution of disparities in knowledge be- tween the groups on 2KE (Tab. 3, Fig. 3). The patients' self-assessed economic status showed no influence on either of the analysed aspects of patients' knowledge. The knowledge of the signs and symptoms of the coronary artery disease and myocardial infarction on $1 \mathrm{KE}$ varied with respect to place of residence (big cities $61.41 \% \pm 25.0 \%$; small cities $48.80 \% \pm 26.85 \%$; villages $54.57 \% \pm 25.23 \% ; p=0.01$ ). No differences with respect to place of residence were found for the 
Table 3. Differences in the level of knowledge of patients at the beginning of hospitalisation (1KE) and at discharge from hospital (2KE) in relation to employment status

\begin{tabular}{|c|c|c|c|c|c|c|}
\hline \multirow{3}{*}{$\begin{array}{l}\text { Question- } \\
\text { naire }\end{array}$} & \multirow[t]{3}{*}{ Range of patients' knowledge } & \multicolumn{4}{|c|}{ Employment status } & \multirow[t]{3}{*}{$\mathbf{p}$} \\
\hline & & \multicolumn{2}{|c|}{ Employed } & \multicolumn{2}{|c|}{ Unemployed } & \\
\hline & & Mean & SD & Mean & SD & \\
\hline \multirow[t]{4}{*}{$1 \mathrm{KE}$} & $\begin{array}{l}\text { Knowledge of signs and symptoms } \\
\text { of the disease }\end{array}$ & 58.99 & 23.10 & 55.57 & 27.49 & NS \\
\hline & Knowledge of the disease & 70.91 & 28.32 & 57.32 & 32.44 & 0.001333 \\
\hline & Knowledge of prevention & 61.31 & 21.51 & 54.36 & 24.23 & 0.021121 \\
\hline & Overall result & 63.13 & 17.77 & 55.40 & 20.67 & 0.003378 \\
\hline \multirow[t]{4}{*}{$2 \mathrm{KE}$} & $\begin{array}{l}\text { Knowledge of signs and symptoms } \\
\text { of the disease }\end{array}$ & 81.21 & 19.76 & 78.26 & 20.92 & NS \\
\hline & Knowledge of the disease & 87.07 & 23.09 & 83.22 & 26.41 & NS \\
\hline & Knowledge of prevention & 74.04 & 17.26 & 71.14 & 18.69 & NS \\
\hline & Overall result & 79.09 & 14.06 & 75.94 & 16.95 & NS \\
\hline $2 \mathrm{KE}-1 \mathrm{KE}$ & Growth of knowledge & 15.96 & 20.29 & 20.54 & 19.12 & 0.047117 \\
\hline
\end{tabular}

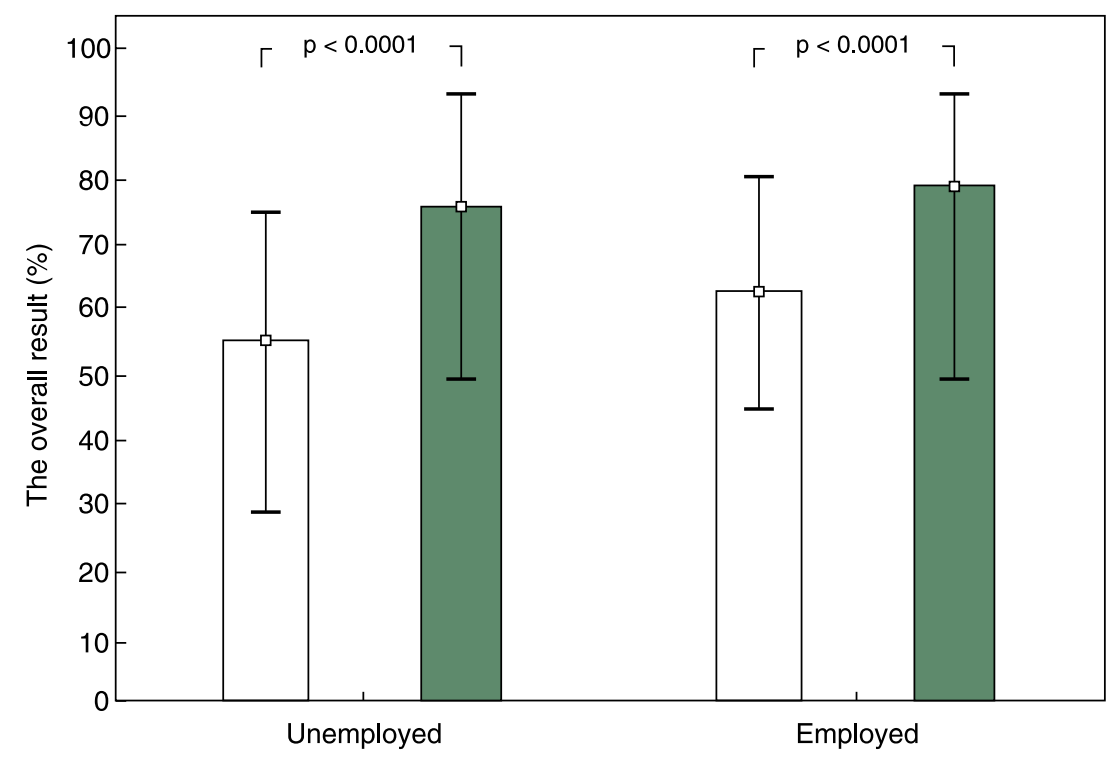

$\square 1 \mathrm{KE} \square 2 \mathrm{KE}$

Figure 3. Evaluation of patients' knowledge at the beginning of hospitalisation (1KE) and at discharge from hospital $(2 \mathrm{KE})$ in relation to employment status

remaining ranges of knowledge on $1 \mathrm{KE}$ nor for any of the ranges of knowledge on $2 \mathrm{KE}$ or the growth of knowledge. The $1 \mathrm{KE}$ did not show any significant differences in patients' knowledge regarding marital status. However, on $2 \mathrm{KE}$ patients remaining in a relationship achieved a significantly better result as compared with single ones (respectively: $86.92 \% \pm 22.80 \%$ vs. $78.79 \% \pm 30.15 \%$; $p<0.03)$. Living alone or with a family did not affect any of the analysed ranges of knowledge on $1 \mathrm{KE}$ or on $2 \mathrm{KE}$.
Consistently with the results of univariate analysis, according to multivariate analysis of baseline knowledge $(1 \mathrm{KE})$, explaining $10.91 \%$ of the variability in the results, two independent factors influencing the knowledge at the beginning of hospitalisation were identified: age $(-3.73 / 10$ years of age; $p<0.0006)$ and education level (secondary or higher vs. primary or vocational). Multivariate analysis of $2 \mathrm{KE}$ explains $7.06 \%$ of the variability in the results. In contrast to 
univariate analysis, the independent factors affecting the level of knowledge after education (2KE) were: age $(-2.04 / 10$ years of age; $p<0.03)$ and remaining in a steady relationship $(9.7 ; p=0.0003)$. According to multivariate analysis (explaining $2.04 \%$ of the variability in the results) the sole factor influencing the growth of knowledge was higher education $(-6.09 ; p<0.02)$. In patients with higher education the growth of knowledge was extremely low - probably due to the fact that the initial level of knowledge in this group was decisively higher and the in-hospital education reduced the level of differences between the groups.

\section{Discussion}

Educational interventions are well recognised, evidence-based means of secondary prevention. They proved to be effective both with reference to endorsement of the recommendations from the therapeutic team by the patient, as well as with respect to active participation of the patient in the process of preparing the personal therapeutic plan [7, 8].

According to our study, brochure-based educational intervention is associated with significant, although still insufficient, growth of patients' knowledge, particularly with regard to prevention.

Studies focusing on the effectiveness of educational interventions deliver conflicting results. Our earlier investigations [6, 9-11] indicate that the level of patients' knowledge with regard to knowledge of the disease and its prevention is unsatisfactory. Baberg et al. [12] also reported a lack of increase in the level of knowledge of the disease and its prevention despite educational intervention in patients with coronary artery disease. On the other hand, Kirk et al. [13] achieved a moderate, but significant increase in patients' knowledge after educational intervention. Brown et al. [14], in their meta-analysis pooling data from 13 clinical studies including 68,556 patients with coronary artery disease showed a trend towards decreased mortality, rate of revascularisation and hospitalisation in patients who underwent different educational programs (ranging from two outpatient visits up to four weeks of hospitalisation).

Our analysis of patients' knowledge of the coronary artery disease, myocardial infarction, and prevention, like numerous other reports [6, 9-11, 15, 16], did not reveal significant differences in this regard between men and women, although some researchers claim such a difference does exist [17]. This, however, does not signify that the knowledge of women and men are at equal levels. As noted by Dorner et al. [18], based on the analysis of activities promoting health in 15,474 respondents, women have lower physical activity, whereas men present worse dietary habits. This research has also shown the influence of age on life-style. Elderly people present lower tobacco dependence, healthier dietary habits, and decreased physical activity. These disparities may, to certain extent, be attributed to differences in knowledge regarding prevention.

In our study, we noted that at the beginning of hospitalisation (1KE) patients above 65 years of age achieved lower results than younger patients in regard to each of the three ranges of knowledge analysed individually, as well as all three of them analysed collectively. This relationship was confirmed by a negative correlation between age and the initial knowledge. Due to greater effectiveness of the educational intervention seen in the older patients, the differences between these age groups observed at hospital discharge were clearly diminished in comparison with the initial assessment. These results are consistent with an earlier study showing a considerably more extensive knowledge of prevention and ischaemic heart disease in patients before 65 years of age [10]. Later research by Kubica et al. [11] showed a significant increase in providing correct answers after educational intervention only in younger patients ( $<65$ years of age).

As reported by Albarqouni et al. [19], older age and lower level of knowledge of signs and symptoms of myocardial infarction contribute to a delay in first medical contact in the case of heart attack.

Our observations indicate a pressing necessity for intensive educational interventions addressed at improvement of knowledge of the disease, signs and symptoms of myocardial infarction, and prevention in patients above 65 years of age.

We have shown that there is a relationship between the level of education and the knowledge owned at the beginning of hospitalisation. Patients with a higher level of education had significantly better knowledge of the disease and its prevention. These patients also achieved the highest overall result in baseline knowledge assessment (1KE). The educational intervention was most effective in patients with the lowest initial level of knowledge, resulting in equalisation of the level of knowledge among the groups on the final evaluation (2KE).

Zama et al. [20] reported that patients who have knowledge of risk factors of cardiovascular diseases attempt to eliminate these risk factors more frequently. They distinguished a group of patients with higher education undertaking much more frequent attempts to give up smoking.

Other studies [11, 21] confirmed that patients with a lower level of education present sparse knowledge of ischaemic heart disease and myocardial infarction. However, in contrast to the results of our research, the effectiveness of education in patients with primary education was low. On the other hand, similarly to 
previously published studies [10,11], we observed that patients with primary education, despite the higher effectiveness of in-hospital, brochure-based education as expressed by a higher growth of knowledge in this group, did not catch up with patients with higher education, achieving the final knowledge level (2KE) merely equal to the baseline knowledge level (1KE) of patients with higher education.

Winkleby et al. [22] already in the mid 1990s pointed to persons with a low level of education and little knowledge as the population that particularly requires education with regard to primary and secondary prevention. This thesis has also been substantiated by Di Chiara et al. [23], who showed a correlation between a lower level of education and prevalence of marked abdominal obesity, and microalbuminuria. Mochari et al. [24] reported that low education and lack of insurance is associated with a lower level of knowledge regarding the optimal values of blood pressure and blood cholesterol concentration, particularly in patients below 45 years of age. A review of literature on the education of patients with cardiovascular diseases shows that Canadian researchers advocate focusing on a group with a low level of health literacy and cognitive skills [25].

Without a doubt, employment is strictly related with the level of education and economic status. These elements interact with each other. However, in our study patients' self-assessed economic status did not have a significant influence on the level of knowledge or the effectiveness of education among myocardial infarction patients. Univariate analysis showed that employed persons had a higher level of baseline knowledge regarding the disease and its prevention. Brochure-based educational intervention balanced the baseline disparities in this regard. However, multivariate analysis did not confirm employment to be an independent factor affecting the level of knowledge or the effectiveness of education.

Yarnell et al. [26] demonstrated a correlation between socio-economic status and the incidence of atherosclerosis risk factors. Persons with lower socio-economic status more commonly had worse results of lipid tests and higher blood levels of glucose. In males, low socio-economic status additionally correlated with increased body mass index and hip-waist index [26]. Filippidis et al. [27] compared health activities in Greece prior to and following the economic crisis in 2008-2011. The authors observed a significant increase in physical activity and a decrease in the rate of smoking habit. At the same time, the frequency of ingestion of at least five portions of fruit and vegetables dropped radically [27].

The last factor analysed in our study was the place of residence. Although it was identified by univariate analysis as a predictor of the knowledge of signs and symptoms of the disease, it did not maintain statistical significance in multivariate analysis.

The results of educational intervention in our study were obtained with use of an arbitrarily chosen brochure and thus may not be valid for other brochures.

To sum up, the multivariate analysis of variables showed that age and educational level are interdependent factors affecting the knowledge level prior to educational intervention. In addition, higher education was identified as the sole independent factor influencing the growth of knowledge during educational intervention. Age and remaining in a steady relationship were the only independent factors showing influence on the knowledge level after educational intervention.

In light of our research, health educational brochures are an effective method of education in patients with myocardial infarction. However, it is important to notice that brochure hand out alone as a source of valid information for the patient is insufficient and requires further motivational back-up. Our results substantiate the need for a better understanding between the patient and a healthcare provider, in pursuit of effective execution of the therapeutic plan.

\section{Conclusions}

1. An educational brochure is an effective tool in therapeutic education of patients with myocardial infarction.

2. Younger patients and those with higher education have better baseline knowledge regarding ischaemic heart disease, its signs, symptoms, and prevention prior to education.

3. Younger patients and those remaining in a steady relationship have better knowledge following educational intervention.

\section{Conflict of interest: none declared}

Acknowledgment: The study was supported by a scientific grant from Nicolaus Copernicus University (No. 547/2016)

\section{References}

1. Nichols M, Townsend N, Scarborough P, et al. Cardiovascular disease in Europe 2014: epidemiological update. Eur Heart J. 2014; 35(42): 2950-2959, doi: 10.1093/eurheartj/ehu299, indexed in Pubmed: 25139896.

2. Wojtyniak B. Choroby układu krążenia jako priorytet zdrowia publicznego. In: Strzelecki Z, Szymborski J. ed. Zachorowalność i umieralność na choroby układu krążenia a sytuacja demograficzna Polski. Rządowa Rada Ludnościowa, Warszawa 2014: 81-100.

3. Gierlotka M, Zdrojewski T, Wojtyniak B, et al. Incidence, treatment in-hospital mortality and one-year outcomes of acute myocardial infarction in Poland in 2009-2012--nationwide AMI-PL database. Kar- 
diol Pol. 2015; 73(3): 142-158, doi: 10.5603/KP.a2014.0213, indexed in Pubmed: 25371307

4. Jankowski P, Niewada M, Bochenek A, et al. Optymalny Model Kompleksowej Rehabilitacji i Wtórnej Prewencji. Kardiologia Polska. 2013 71(9): 995-1003, doi: 10.5603/kp.2013.0246.

5. Kubica A, Grześk G, Grąbczewska Z. Choroby układu sercowo -naczyniowego - wyzwanie dla promocji zdrowia. Cardiovascular Forum 2006: 11: 44-47.

6. Kubica A, Pufal J, Moczulska B, et al. Skuteczność edukacji zdrowotnej u osób hospitalizowanych w klinice kariologii. Psychiatr Prak Ogólnolek. 2005; 5: 61-68.

7. Kubica A, Kasprzak M, Obońska K, et al. Discrepancies in assessment of adherence to antiplatelet treatment after myocardial infarction. Pharmacology. 2015; 95(1-2): 50-58, doi: 10.1159/000371392, indexed in Pubmed: 25592409

8. Kubica A, Kasprzak M, Obońska K, et al. Impact of health education on adherence to clopidogrel and clinical effectivness of antiplatelet treatment in patients after myocardial infarction. Folia Medica Copernicana. 2015; 3: 154-159

9. Kubica A, Olejarczyk E, Jurek A, et al. Wpływ wybranych czynników ryzyka na poziom wiedzy i skuteczność edukacji zdrowotnej u osób z zawałem serca. Czynniki Ryzyka. 2008; 2: 10-18

10. Kubica A, Pufal J, Moczulska B, et al. Ocena wiedzy dotyczące profilaktyki i objawów choroby niedokrwiennej serca u osób hospitalizowanych w klinice kardiologii. Psychiatr Prakt Ogólnolek. 2004; 4(3) 135-141

11. Kubica $A$, Jurek $A$, Olejarczyk $E$, et al. Wybrane czynniki demograficzno-społeczne a skuteczność edukacji zdrowotnej prowadzone na podstawie broszur edukacyjnych u osób z ostrym zawałem serca. Folia Cardiologica. 2008; 3(4): 199-207.

12. Baberg HT, Jäger D, Kahrmann G, et al. Health promotion and cardiovascular risk factors. The level of knowledge among 510 inpatients of an acute coronary care unit. Med Klin (Munich). 2000; 95(2): 75-80, indexed in Pubmed: 10714122

13. Kirk-Gardner R, Steven D. Hearts for Life: a community program on heart health promotion. Can J Cardiovasc Nurs. 2003; 13(1): 5-10, indexed in Pubmed: 12703099.

14. Brown JPr, Clark AM, Dalal $\mathrm{H}$, et al. Patient education in the management of coronary heart disease. Cochrane Database Syst Rev. 2011(12): CD008895, doi: 10.1002/14651858.CD008895.pub2 indexed in Pubmed: 22161440

15. Haidinger T, Zweimüller M, Stütz L, et al. Effect of gender on awareness of cardiovascular risk factors, preventive action taken, and barriers to cardiovascular health in a group of Austrian subjects. Gend Med. 2012; 9(2): 94-102, doi: 10.1016/j.genm.2012.02.001, indexed in Pubmed: 22440721
16. Lechowicz M, Wiliński J, Kameczura T, et al. Awareness of cardiovascular risk factors in ambulatory cardiology patients. Folia Med Cracov. 2015; 55(2): 15-22, indexed in Pubmed: 26839239.

17. Awad A, Al-Nafisi H. Public knowledge of cardiovascular disease and its risk factors in Kuwait: a cross-sectional survey. BMC Public Health. 2014; 14: 1131, doi: 10.1186/1471-2458-14-1131, indexed in Pubmed: 25367768.

18. Dorner TE, Stronegger WJ, Hoffmann K, et al. Socio-economic determinants of health behaviours across age groups: results of a cross-sectional survey. Wien Klin Wochenschr. 2013; 125(9-10): 261-269, doi: 10.1007/s00508-013-0360-0, indexed in Pubmed: 23579882

19. Albarqouni L, Smenes K, Meinertz Th, et al. Patients' knowledge about symptoms and adequate behaviour during acute myocardial infarction and its impact on delay time: Findings from the multicentre MEDEA Study. Patient Educ Couns. 2016; 99(11): 1845-1851, doi: 10.1016/j. pec.2016.06.007, indexed in Pubmed: 27387122.

20. Zaman MJ, Patel A, Jan S, et al. Socio-economic distribution of cardiovascular risk factors and knowledge in rural India. Int J Epidemiol. 2012; 41(5): 1302-1314, doi: 10.1093/ije/dyr226, indexed in Pubmed: 22345313.

21. Giardina EGV, Mull L, Sciacca RR, et al. Relationship between cardiovascular disease knowledge and race/ethnicity, education, and weight status. Clin Cardiol. 2012; 35(1): 43-48, doi: 10.1002/clc.20992, indexed in Pubmed: 22083540.

22. Winkleby MA, Flora JA, Kraemer HC. A community-based heart disease intervention: predictors of change. Am J Public Health. 1994; 84(5): 767-772, indexed in Pubmed: 8179046

23. Di Chiara T, Scaglione A, Corrao S, et al. Association between low education and higher global cardiovascular risk. J Clin Hypertens (Greenwich). 2015; 17(5): 332-337, doi: 10.1111/jch.12506, indexed in Pubmed: 25703272

24. Mochari H, Ferris A, Adigopula S, et al. Cardiovascular disease knowledge, medication adherence, and barriers to preventive action in a minority population. Prev Cardiol. 2007; 10(4): 190-195, indexed in Pubmed: 17917515.

25. Ghisi GL, Abdallah F, Grace SL, et al. A systematic review of patient education in cardiac patients: do they increase knowledge and promote health behavior change? Patient Educ Couns. 2014; 95(2): 160-174, doi: 10.1016/j.pec.2014.01.012, indexed in Pubmed: 24529720.

26. Yarnell J, Yu S, McCrum E, et al. PRIME study group. Education, socioeconomic and lifestyle factors, and risk of coronary heart disease: the PRIME Study. Int J Epidemiol. 2005; 34(2): 268-275, doi: 10.1093/ije/dyh267, indexed in Pubmed: 15319403.

27. Filippidis FT, Schoretsaniti S, Dimitrakaki C et al. Trends in cardiovascular risk factors in Greece before and during the financial crisis: the impact of social disparities. Eur J Public Health. 2014; 24(6): 974-979, doi: 0.1093/eurpub/cku028, indexed in Pubmed: 24614651. 